\title{
Communication in Diagnostic Radiology
}

\author{
HARRY W. FISGHER, M.D.* \\ From the Department of Radiology, Wayne County General Hospital and the University of Michigan, \\ Department of Radiology, Ann Arbor, Michigan
}

This paper was presented at a Symposium "Ueber Aktuelle Probleme der Röntgendiagnostic" which was given to formalize the opening of the Roentgen Diagnostic Department at the Central Institute of the University of Bern and the Inselspital of Bern, September 1, 1970.

\section{INTRODUCTION}

The radiologist has become increasingly more important to his medical colleagues. He is now able to provide solutions he formerly could not, or did not attempt, and to provide more precise complete or more confident answers than formerly were available. His medical colleagues have grown accustomed to an everwidening variety of radiological examinations. The radiologist and his technicians formerly performed relatively simple, quickly completed examinations and the radiologist interpreted these examinations. Now a progressively larger portion of the radiologist's time is spent conducting more lengthy complicated examinations in which he is the indispensable man, while the volume of technician-performed examinations which he continues to interpret ever increases.

The population grows and living standards rise, the people demand more of all medical services. Medical care is being expanded to segments of the population which previously had little, while other segments are advancing from receiving attention only during catastrophic illness to comprehensive care. As the older portion of our population increases as it is doing now, density of $x$-ray examinations will increase. As the population becomes more urbanized, density will also predictably rise. Many of the world's peoples have become more prosperous than ever before. The patient has become of more value, and is more demanding. The desire to live is greater and resistance to suffering is lower. ${ }^{1}$ The rising activity in research in diagnostic radiology plus the involvement of the diagnostic radiologist in therapeutic procedures also adds to the radiologists' activity.

The forces creating a great demand for diagnostic radiology services can be gauged in part by the consumption of $\mathrm{x}$-ray film which has increased at the rate of $5.4 \%$ annually in the United States, or a doubling rate every 13

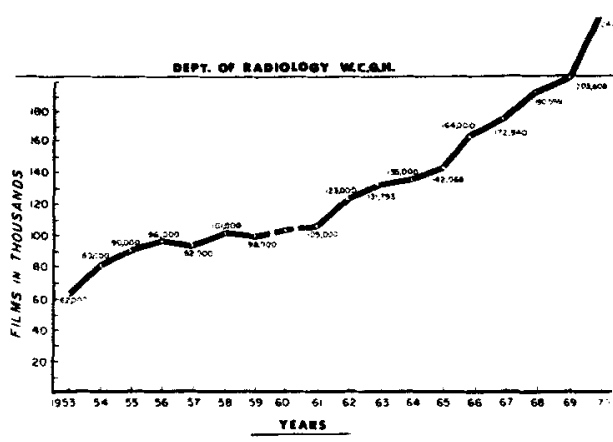

FIGURE 1.-The consumption of $x$-ray film at the Wayne County General Hospital has risen from 62,000 yearly in 1953 to 240,767 yearly in 1970 . The increase in consumption rate for the United States has been $5.4 \%$ annually or a doubling rate every 13 years. $^{2}$

years $^{2}$ (Figure 1). Complex time-consuming examinations however, require about $25 \%$ of the professional manpower. These examinations are less than $3 \%$ of the total examinations and have little influence on film consumption statistics, suggesting film consumption at most reflects only of the total demand for diagnostic $x$-ray service. ${ }^{2}$ In the academic institutions and large medical centres, the expansion of activity is probably in excess of the general average of $7.2 \%$. One centre reports an increase of $14 \%$ in number of examinations yearly and estimates because of the complexity of the aforementioned special procedures, an increase of $\mathbf{4 0} \%$ yearly in the workload. ${ }^{3}$

In other countries the number of examinations has increased at the rate of $8.5 \%$ yearly (Netherlands), between 5 and $10 \%$ yearly (Sweden), in France and in Germany $10 \% .1$ $\mathrm{X}$-ray film consumption, and the number of $x$-ray technicians has increased yearly in the

* Present address: Department of Radiology, University of Rochester School of Medicine and Dentistry, Rochester, N.Y. 14642 .

Australasian Radiology, Vol. XVI, No. 1, March, 1972 


\section{Communication in Diagnostic Radiology}

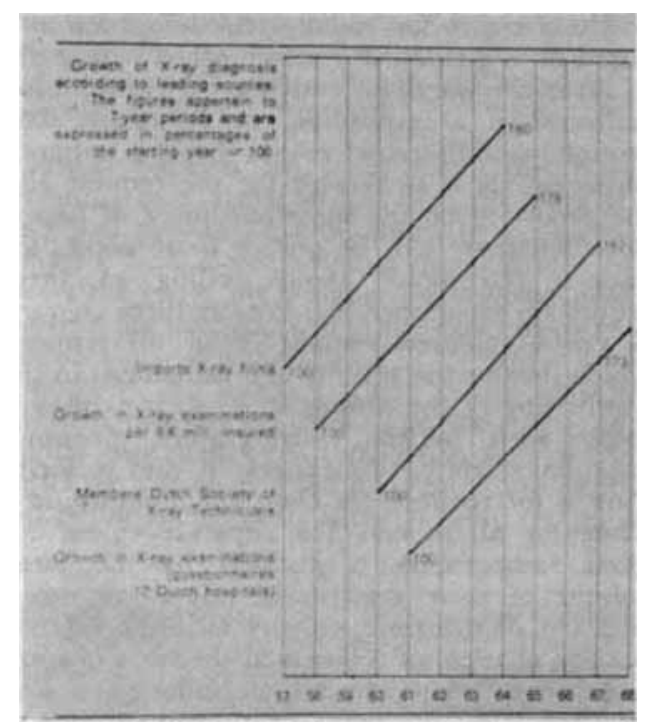

Figure 2.-The number of x-ray examinations in the Netherlands has increased at the rate of $8.5 \%$ yearly. $X$-ray film consumption, the number of $x$-ray technicians, and the density of $x$-ray examinations per 1000 population per annum has increased in similar degree." (Graph by courtesy of Puijalaert \& Medicamundi).

Netherlands at the same rate, as has the density of number of examinations per 1000 population per annum (Figure 2).

The demand for radiological services has created a shortage of radiological personnel. Projected supply-demand figures as rough and incomplete as they are imply a drastic shortage of both academic and practising radiologists within the next five years, sufficient to hamper the diagnostic and therapeutic work of the physician and surgeon. ${ }^{4} \mathrm{~A}$ shortage of crisis proportions is predicted with certainty by 1975.4 The scarcity of diagnostic radiologists is particularly felt in academic radiology. 5 The academic radiologist is often so completely occupied by service needs that he has no time for scholastic pursuits, ${ }^{3}$ and Knowles has written that a global shortage of academic radiologists cannot be denied.4 To satisfy the need for radiologists in the United States by 1975 would require over $20 \%$ of medical school graduates to enter training in radiology, a figure most unlikely to be obtained despite heroic efforts in honorable recruiting or even seduction. ${ }^{B}$ Likewise, in the Netherlands where ten to fifteen radiologists are added each year, an additional 400 radiologists (disregarding natural losses due to retirement or death) in the next ten years appears to be needed, a comparable but also likely unreachable goal.

Other solutions to this seemingly insoluble problem are to be considered. It has been proposed to delegate professional activities of the radiologist to subprofessional personnel or to surrender to well-trained specialists in their own area of interest certain activities now considered in the province of the radiologist, or to increase the effectiveness of the radiologist by having him function with increased efficiency in his professional activities and to have him perform as little non-professional activity as possible.

No one can predict the relative value of each of the solutions or the extent to which they will be applied, because of differences in viewpoints of individuals and regional or national organizations of radiologists. Medical practice, and radiology in particular, is a problem solving activity requiring clinical knowledge. Were radiology merely a pattern recognition activity which could be taught through repetitive experience, transfer of professional activity in both performance and interpretation to nonprofessional could be accomplished, but the interpretation of information in radio-diagnosis requires knowledge and intellectual activity characteristic of professional behaviour. True, some of diagnostic radiologic activities are of a nature that can be taught to non-professionals. Encouraging results indicate this approach should be and will be further explored. $(7,8,9)$ The surrender of performance of radiologic examinations and interpretative activity to gastroenterologists in contrast studies of the alimentary tract, to chest physicians in studies of the chest, to neurologists and neuro-surgeons in studies of the nervous system, is not new. This approach cannot be discussed unemotionally by radiologists since it strikes at the idea of the radiologist having a special competence and would lead eventually to emasculation, if not destruction, of the specialty. As much as man is given to self destruction, the radiologist will not consciously plan and begin to carry out the death of his own specialty. Most attractive and most attainable of proposed solutions is to have the radiologist function with higher efficiency in his professional activities and to have him delegate non-professional activities to others. To this end "Every modern educational, administrative, and technological means must be investigated to improve the efficiency with which radiological services are provided". 2 The radiologist must retain a maximum of his time and effort for his truly professional activity 
which is the obtaining of radiological information and the communication of this information to his colleagues. The time spent by the radiologist in non-professional, clerical, communicative, and administrative activities must be reduced to the bare minimum.

The radiologist should utilize all means of communication to function at maximum efficiency. The radiologist should perfect the means of non-personal communication to allow maximum time for and to excel in person-to-person cormunication with his clinical colleagues, for teaching person to person and doing research.

Communication in the radiology department can be divided into communication for the benefit of the immediate patient and for the benefit of the future patient. The first involves the communication within the department to expedite movement of patients, and movement of information related to the patient such as schedules, filing reports, and the $x$-ray images themselves. All of this communication is devoted to obtaining and transmitting $x$-ray information so that the immediate patient undergoes the minimum of inconvenience and discomfort, and the radiologist functions with maximum efficiency in a minimum of time.

By communication for the benefit of the future patient we mean the communication the radiologist uses in teaching. In the academic situation these types of cornmunication are relatively well developed for the technician, the technician student, the medical student, the radiology resident, the physician practicing or in training in other disciplines, and the radiologist himself. In other hospitals teaching is less well developed but not absent. Of course, some of the communication for the benefit of the immediate patient is also used in teaching, and the immediate patient benefits from previous teaching.

\section{The Daily Functioning of the Radiology DEPARTMENT}

The methods of communication needed for efficient functioning of a radiology department can conveniently be considered in relation to the patient's travel to and through the department and the interpreting and reporting of the information gained from the examination. The making of exposures in an average hospital calls for at least twelve separate work steps, the interpretation and reporting nine additional work steps. ${ }^{10}$ Each of these steps requires departmental members to communicate with another.
The request for radiological information is based on a written document, which we prefer to term a request for radiological consultation rather than a requisition, or an order. The request is initiated of course by the patient's physician. It is preferable for the request and the report to be the same one piece of paper, of which there can be one or more copies for various purposes. Colour coding of these requests is recommended. We use three colours. A green coloured request is for all requests which involve the activity of a radiologist in the conducting of the examination, such as fluoroscopy with barium, angiography, pneumoencephalography, bronchography and so forth. Pink is for requests for chest radiography, and white for all others. The separate colour for chest radiography is justified by the large volume of these requests in any department. The use of the three colours facilitates identification of types of requests in the steps of communication before, during, and after the actual examinations. The request form should have in addition to the original or face copy which is returned to the physician or to the patient's chart with the radiologist's report, a copy for the radiology department records, a billing copy, and other copies which may be desired for administrative or statistical purposes.

Although it is realized a portion of the work of any department is of an emergency or unforeseen nature or at the discretion of clinics or referring physicians whose own work is unscheduled, scheduling can be done within the hospital by telephone or voice inter-com. It may be more efficiently done by written mes. sage transported by a pneumatic tube system for example, or better electronically as by teletype machine. When telephone or intercom are used, the departmental employee must attend that unit at the will of others, whereas when visually displayed messages are used the clerk may more conveniently allot her own time, provided messages received are answered within a fairly short time. The advantages of scheduling are better distribution of the department work load, more efficient use of transportation personnel, better instructions to the hospital floors and dietary department and clinics. Probably the most efficient means of scheduling will be the computer. The clerk will relay the physician's request to the radiology department computer from terminals on the wards and clinics, a valuable aid in this being a machine readable card to identify each patient. The computer then makes a response to the initiating terminal giving a designated time and instruc- 


\section{Communication in Diagnostic Radiology}

tions for examination, and notification to other terminals for transportation and diet changes and to the file room for withdrawal of prior films. $(12,19)$

When patients are scheduled, the x-ray personnel may learn in advance the patient's record of previous examinations by consulting a master card file. A rotating motor driven file allows the clerk, by pressing of a coded button, to bring the tray containing the cards of correct alphabetical designation quickly into view (Figure 3). No longer is there reason to store cards in pull-drawer files. The old films and reports can then be withdrawn from the film file so the radiologist can plan the examination and better interpret it. If the patient arrives in

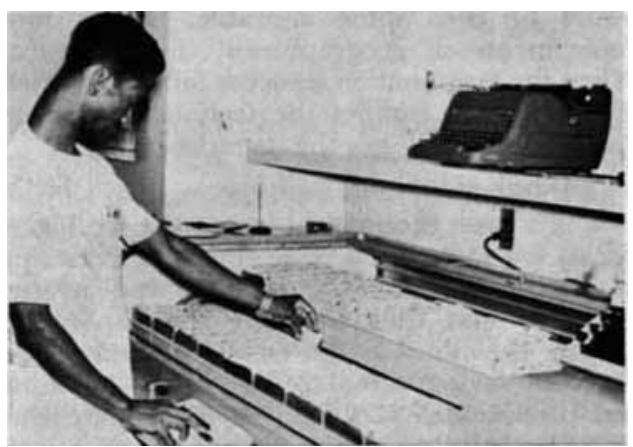

Figure 3.-A motor driven rotating file saves much time over conventional drawer filing cabinets. The sought portion of the alphabet is brought into view by pressing the appropriate coded button on the control panel.

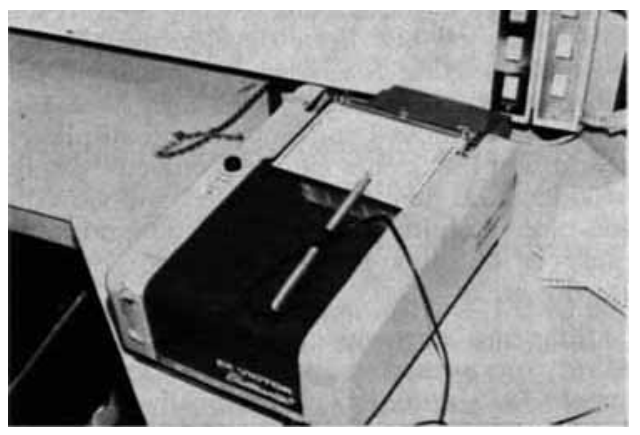

Frgure 4.-The "Electrowriter" is an electronic device which can be used for transmitting a handwritten message from one location to another in the Radiology Department, or from the Radiology Department to another part of the hospital, such as to the Emergency Room for preliminary reports on trauma or acute illness cases. ${ }^{14}$ (See also Figure 13). the department unscheduled, the file personnel must be quickly notified so the prior examinations and reports can be furnished to the radiologists. For this we advocate an electronic device (Electrowriter), ${ }^{14}$ (Figure 4), which will transmit a brief written message to the file room from the periphery of the department where the patient is first seen. Two or more master units can signal to a single "slave" unit in the file room. Teletype or pneumatic tube system could likewise function in this capacity as would a closed circuit TV with keyboard, but (Figure 5) the latter is more expensive. A CCTV without keyboard but with camera focused on a chalk board is also a possibility. The electrowriter has the advantage of permanent recording at the receiving unit. It need not be constantly attended as would be necessary for voice communication. The computer can also be used for signalling the film room when the patient arrives in the department unscheduled.

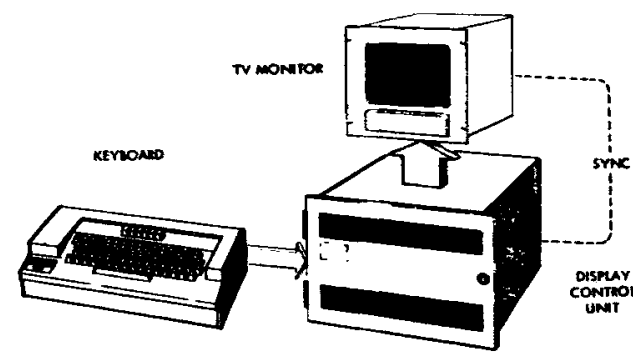

Figure 5.-A closed circuit TV system with keyboard useful for transmitting information in the Radiology Department, but is more expensive than simpler apparatus.

While the patient is being $x$-rayed, the film room personnel obtain the film file envelope containing the prior examinations or prepares a new envelope for the new patient. Efficiency in retrieving the patient's old envelope depends in large part on the method of filing. We advocate an envelope with terminal digit, colour coded numbering for the ease of filing (Figure 6). Filing errors are virtually eliminated because of the clash of colour of the misfiled envelope among the juxtaposed correctly filed envelopes (Figure 7). The file in this system has an equal distribution of envelopes in each section, and recent films are not concentrated at one end of the file. ${ }^{13}$ By labelling the envelopes with the last digit of the year of last examination (9 for 1969,0 for 1970,1 for 1971) the active file may be easily winnowed for the least active cases which may then be sent to a less active storage area. If about two to three years of the most recently used envelopes can be kept in a very 


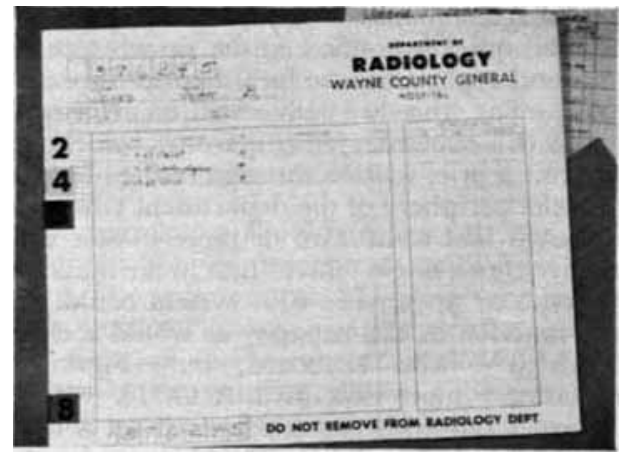

Figure 6.-The large envelope which holds the $x$-ray films can be filed, located, and refiled most easily if colour coding of its terminal digits is used. The envelope opening at the top edge allows easier insertion and removal of films. The year of last usage is designated by the lower numbers "9" for 1969, "0" for 1970. Other codes can be used on the remaining edge space.

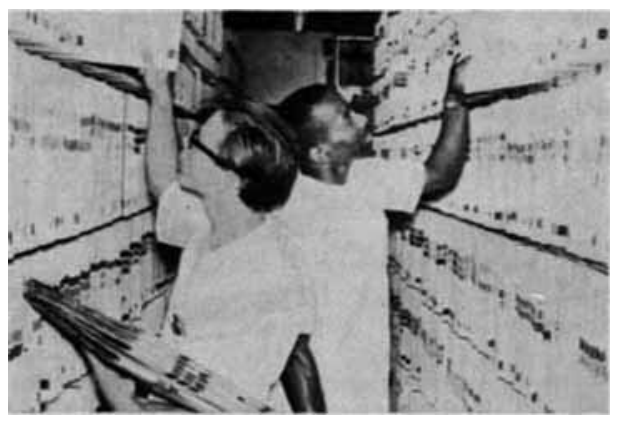

Figure 7.-Misfiling is essentially impossible when colour coding is used of numbers, and moreover the file has an aesthetic appearance.

close physical relationship to the film assembly or "make-up" area, retrieval of desired envelopes is greatly expedited since the majority of demand is for the envelopes of the recent period. A top opening envelope is easier for insertion and removal of films. A good filing system and good personnel need never make the radiologist wait to see old examinations, or prevent him from seeing them because they are lost.

With the completion of processing of current films the information in this form and the accompanying information on paper ( $x$-ray request) must be transported or transmitted to a suitable area along with prior films. TV tapes and cine films are to be likewise transported when they are available. A suitable, convenient display area is all important. There the radiologist in- stitutes control of the quality of the examination, makes his interpretation and his official report. The ideal is to have the outlet of the processing unit and film assembly room closely adjacent to this viewing area, this closeness being highly desirable if not necessary to eliminate one of the problems of communication, namely the transportation of films from processor to the viewing area. To notify technicians and clerical personnel the examination has been completed successfully or to instruct the technicians in correction of errors or to further adapt the examination to the patient's problem, intercom system should be used liberally. Written messages transmitted electronically are less desirable since radiologist to technician voice contact is more effective and better for employee morale. Face-to-face communication would be even more desirable, but in most departments is geographically not practical. When the examination is successfully completed, the radiologist notifies the technician or clerk the patient may leave the department.

In transport of films from processor to viewing area it is most economical to use the services of clerks, not radiologists or technicians. Personnel can be trained to transport films and arrange a display and then disemble the display, returning the films to the envelopes and to the file, thus saving valuable time of the technical and professional personnel in the department. Motorized multi-views can be used effectively in display of large volume of films. If the multiviews themselves are mobile there is the advantage afforded of loading films in one area, and viewing, interpreting and holding a conference with them in another. They are then assembled in another or in the original loading area. A unit of new design has been developed at Lund, Sweden, the Auto-Alternator, employing a cartridge of separate frames which may be loaded in one area, moved to another and displayed. In addition the frames can be removed from the cartridge and loaded or viewed individually. Non-mobile multiviewers of other design require transport of films to them from original reviewing areas.

Filing and retrieval of films today is almost entirely performed manually by clerical personnel. An automated electronically controlled film filing and retrieval system has been developed.16 (Figure 8). It would be speedy and would do away with the need for personnel to carry envelopes to and from shelves, and to search for envelopes. Number, date, and other information can be placed on a magnetic tape on the jacket, which can be read by the electronic device. ${ }^{16}$ 


\section{Communication in Diagnostic Radiology}

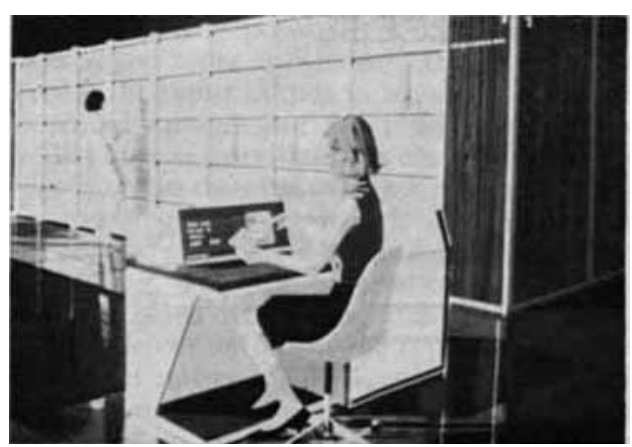

Figure 8.-An automated electronically controlled filing system has been developed which speedily files and searches for and retrieves film envelopes. ${ }^{16}$ (Photo courtesy of General Electric Co.).

The future may hold the possibility of storing the $x$-ray images not as films but video tape or video disc recordings. The main limitations appear to be inferior quality of the videodisc image to most radiologists, the expense of installations, and the degradation of the images through electronic noise which increases progressively with each transfer from tape to disc and return. ${ }^{17}$ It is estimated one 3000 foot reel of videotapes can store the images of 70 discs, each disc capable of obtaining 1600 images. Combination of disc storage is also envisioned with the continued production of conventional $\mathrm{x}$-ray films which would be filed and indexed separately. Videotape and disc recording and storage has the advantage of rapid availability to multiple areas in the department and hospital without physical movement of personnel from place to place, such availability being limited only by wiring and number of video monitors.

Immediate hospital-wide access to $x$-ray film images can be obtained with a system of TV cameras, monitors, videodisc recorders, and their connecting cables and appropriate switches. ${ }^{18}$ (Figure 5). In the radiology department, an x-ray film is viewed by a TV camera at the same time another TV camera views identification information. A special effects generator combines the two images. Simultancously this image is seen on the TV monitor in the radiology department, and recorded on videodisc recorders in the radiology department and in the patient's ward or clinic. Immediately or at any later time thereafter the patient's physician is able to view the image on his local disc recorder.
Rather than storing films, the films may be viewed by TV camera and transferred to videodisc. The $\mathrm{x}$-ray images then can be transferred from disc to a video tape and stored. To retrieve an $x$-ray image, the particular image, with the aid of an indexing system is located on the tape and then transferred back to a videodisc. Viewing may then take place in the radiology department or the image may be transmitted to a remote location, a clinic, a ward or conference room. With such a system the actual films, once they are electronically recorded, need not leave their file envelopes after filing, nor need the films and envelopes leave the radiology department. The system would be expensive to install, being estimated for one hospital as approximately equal to the file room personnel cost for two years. 18 Objections in addition to cost, are the risk of loss or degradation of images through technical electronic difficulties in the videodisc and videotape systems, and the inferior quality of the videoimage to most radiologists. The developers intention is that the original $x$-ray films would be interpreted and reported and filed by conventional means, although the images have also been televised, so that losses could be retrieved and the original films reviewed if image quality dictates.

Of course, the making of films can be omitted with suitable instrumentation to place the $x$-ray image directly on a videodisc recorder. All the above described steps then apply, but such a system would not have the desired backup feature of the image on film.

Closed circuit TV units have been put to good use in several ways for better communication in radiology departments. The monitoring of barium fluoroscopic procedures or an angiography procedure by a teaching or supervising radiologist is well known, as is the use of a circuit to an auditorium or conference room for teaching purposes. Closed circuit TV can also be used for film quality control when the one to oversee the films cannot be physically close to the automatic processor, or alternately when the controller is located at the automatic processor and needs to illustrate errors to the technician who is at some distance from him. As mentioned before, such instructions can be given well by voice intercom but are often better communicated visually in addition to orally. Circuits are also useful for demonstrating the films to the surgeons in the operating room, or to emergency room physicians. The demonstration of operative cholangiograms is a particular appropriate use for the surgeon, so that the radiologist need not enter the sterile area and 


\section{IMMEDIATE HOSPITAL-WIDE ACCESS TO $\times$-RAY FILM IMAGES}

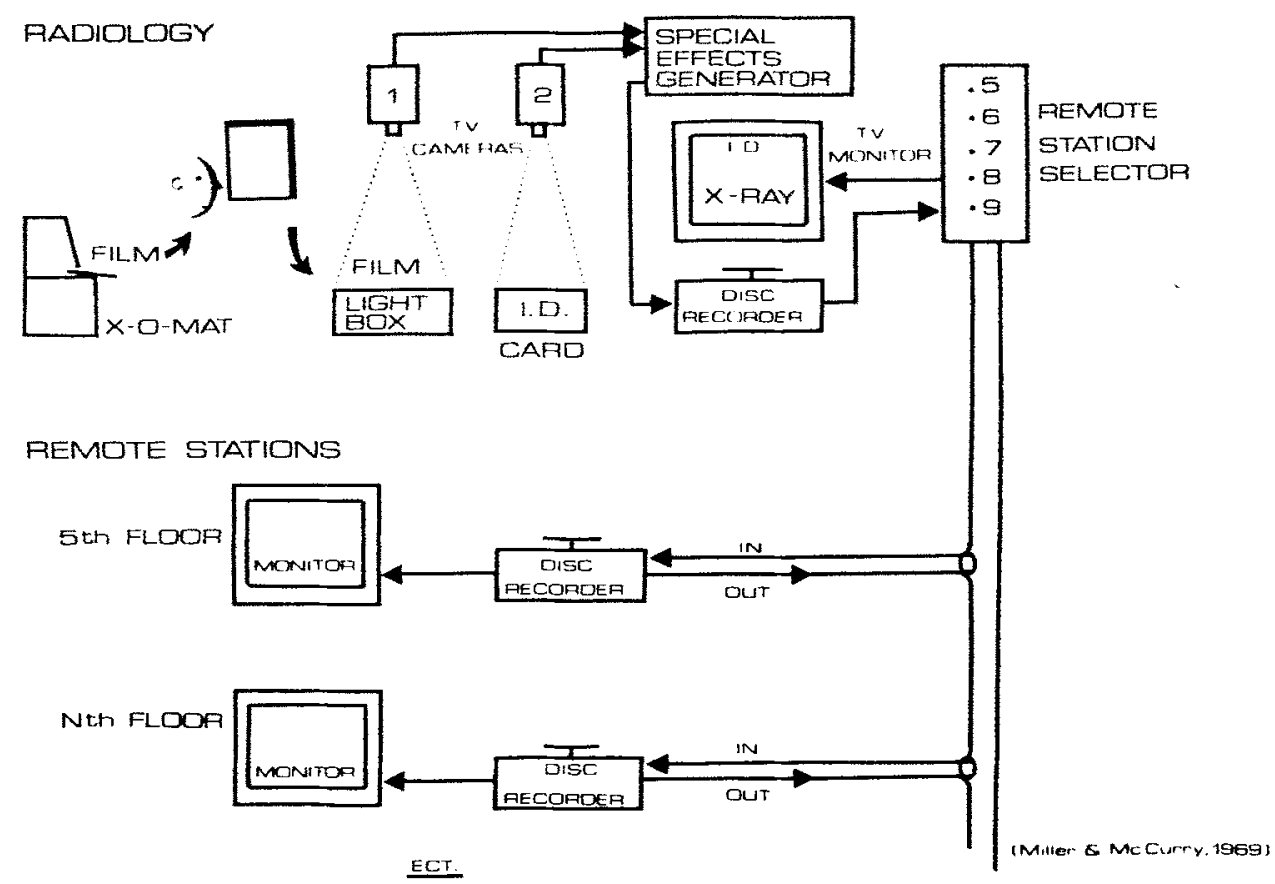

FIGURE 9.-Immediate hospital-wide access to x-ray film images can be obtained with a system of TV cameras, monitors, videodisc recorders, and their connecting cables. ${ }^{17}$ (After Miller \& Curry).

yet he can communicate with speed and accuracy while he discusses the films on the viewer and the surgeon watches the operating room monitor. Information on patient records can also be transmitted by closed circuits, Waiting rooms can be observed, and seriously ill or difficult to manage patients can be monitored more efficiently.

In the viewing area the radiologist may dictate directly to the stenographer or indirectly to a stenographer via magnetic tape or belt. The stenographer then converts the spoken words to print with a typewriter. The radiologist's report must be brought to the attention of the patient's physician as soon as possible, however, considerable time lags are experienced between dictation and actual arrival of the report in the physicians' hands, due to in part the time needed for the typist to receive and perform her work, the radiologist to approve it or correct it, the typist to incorporate the corrections, the radiologist to sign it. Finally the report must be delivered. During all this time, the report is frequently unavailable to other hospital personnel. A person dictating does so at an average rate of 80 words per minute and 20,000 words per day, while the average typist transcribes reports at the rate of 20 words per minute, and 6,000 words per day. 19 Direct dictation is therefore wasteful of radiologist's time, if he is forced to gear his dictation to typist's rate. There are other disadvantages of typewriter noise and pre-empting of valuable space by the typist. Direct dictation is also wasteful of typist's time since she is unoccupied when the radiologist is not dictating. Indirect dictation, as a consequence, is almost universal. A system to increase radiologist's and typist's efficiency consists of multiple dictation locations, a long master recording tape, electronic selective circuitry, and multiple typist stations, so that typists may transcribe from the master tape at any point in time of the preceding dictation, while the radiologist continues to dictate. This obviates the need for multiple tapes 


\section{Communication in Diagnostic Radiology}

or belts and the possibility of misplaced, lost or destroyed tapes and belts. ${ }^{19}$ It is also said to increase the typist output to 30 words a minute. The disadvantages are the total incapacity of the dictation-transcribing system of a radiology department in the event of dysfunction of the all encompassing system, which is not experienced with separate units and tapes for dictation and transcribing, and the system becoming nonfunctional when overloading of the system occurs due to deficient output by the typists. At present a system of this type functions well in handling surgeons and internists dictations of reports and notes in the Wayne County General Hospital.19

An automatic typewriter (Figure 10) is capable of typing standardized reports flawlessly at the rate of 125 words per minute, ${ }^{20}$ as compared to average typist's 20 . Since our department has a workload, 20 to $25 \%$ of which may be handled by a standardized negative report, typists time saving is realized by use of the automatic typewriter. Dictation is also minimized since only the number of the reports needs to be designated. Since the automatic typewriter performs without typographical error, proofreading is not necessary, a further efficiency.

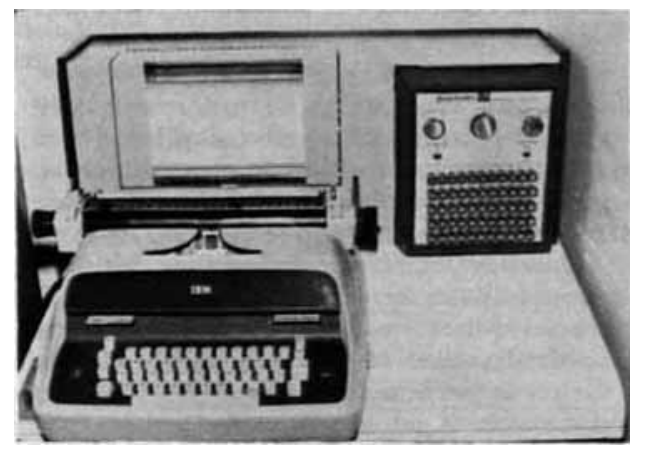

FIGURE 10.-An automatic typewriter is useful for quickly and flawlessly typing standardized negative $x$-ray reports. Each number for selection types a specific report. ${ }^{19}$

Placement of the finished report in the hands of the physician on hospital ward, clinic, or office may then be accomplished by messenger, or by a conveyor system such as a pneumatic tube or movable belt or wire. The typed report may also be sent by teletype or by facsimile device (Figure 11). If the teletype apparatus device is used, proofreading is either omitted which is not desirable, or the typist must do extra work in retyping the corrected report.
With the facsimile apparatus the original report or the corrected report is fed into the machine which transmits it without retyping.

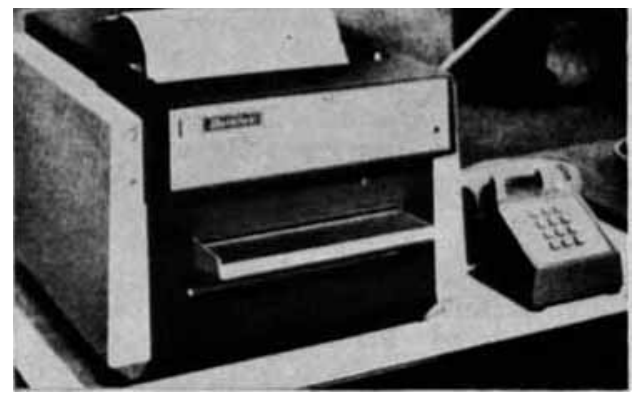

Figure 11.-. The facsimile machine is capable of transmitting a copy of the radiologists report to other parts of the hospital.

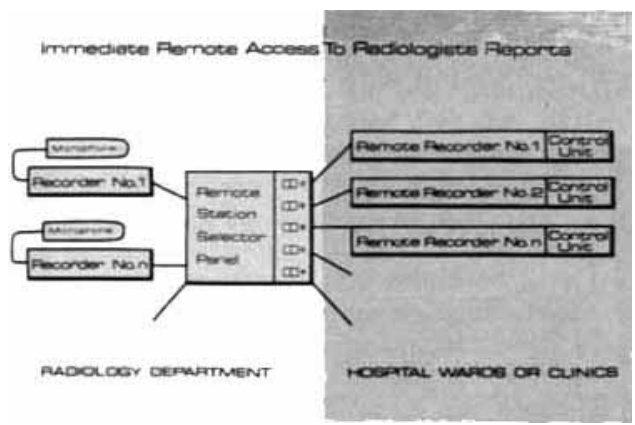

FiguRE 12.-Other areas of the hospital can have access to radiologists' reports by linking together magnetic dictating machines. ${ }^{20}$ (After Miller, E. A., of al.).

Immediate, remote access to the radiologist reports can be obtained by linking together magnetic dictating machines in the radiology department with others in wards and clinics 21 (Figure 12). A selector panel allows the radiologist to direct his report to one of the specified locations and to his own dictating machine simultaneously. There may be as many input or dictating units in the radiology department and as many remote receiving units as needed for the department and hospital size. By this means, the physicians on the wards or in the clinics have sent to them radiology reports without their journeying to or calling the radiology department. The ward or clinic clerk may transcribe a report for the physician to see. The official report for inclusion in the patient's permanent record should still be transcribed from the dictating machines in the radiology department where the radiologist has the opportunity to edit his dictated report. ${ }^{21}$ 


\section{HARRY W. Fischer}

An electronic device, the Electrowriter ${ }^{14}$ (Figure 4) is useful in transmitting brief handwritten reports of radiologic examinations (Figure 13). It is used effectively for communication from the Radiology Department to the Emergency Room for sending a brief preliminary interpretation of the $x$-ray examination of the injured or acutely ill patient. The copy received in the Emergency Room is available for the busy, hurried emergency room physician to read when it is convenient for him to do so and he need not be called to the telephone or an inter-com unit to receive a spoken report. The written preliminary report becomes part of the hospital record (Figure 13). Since this is a hand-writing transmission device, it is obviously not useful for large volume report transmission.

Probably the most efficient way to file all reports, retrieve old reports and to get the new report to the physician will be by employment of a computer with its input units in the department and output units in appropriate locations

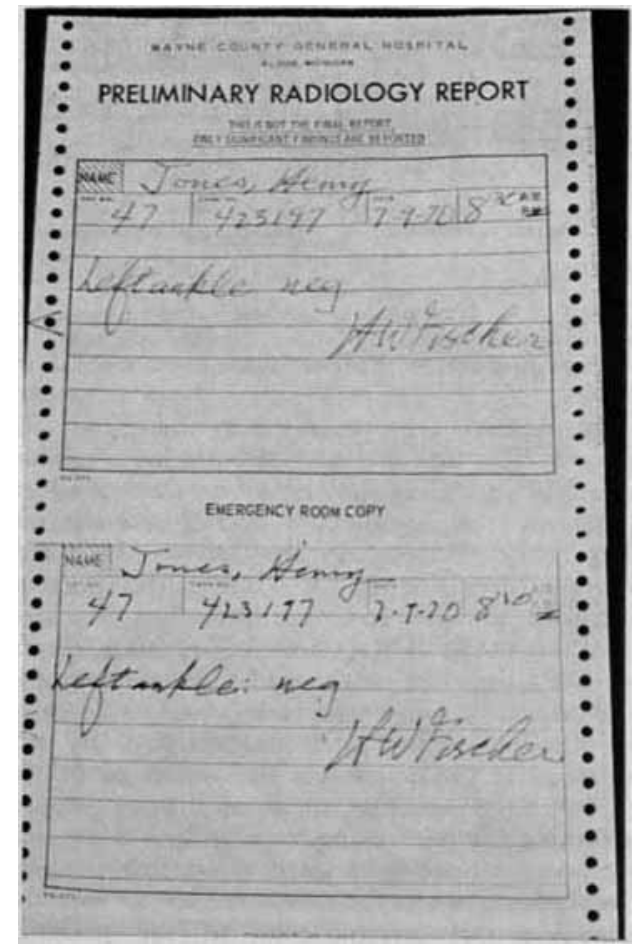

Figure 13. -The "Electrowriter" report received at the remote or "slave" station is compared to the original made within the department, at the "master" station. Its readability is apparent. (See FIGURE 4). throughout the hospital, as well as in the department. It is possible to place the entire report in the computer or to encode the information in some way to simplify its insertion. The computer seems to be the most promising for efficiency in filing and retrieving radiological reports, ${ }^{12}, 22,23,24,25,26,27$ but there is a high initial cost to institute the system, and it is difficult to demonstrate immediately a high benefit to cost ratio. ${ }^{25}$ One of the big problems in the use of computers for storage and retrieval of $x$-ray reports is the development of a suitable input form. Several attempts have been made to improve dictation techniques, to shorten the reports while maintaining clarity and preciseness.

At the University Hospital of the University of Michigan, Dr. John Thornbury ${ }^{28}$ has examined conventional prose radiological reports with a view to retaining significant information while deleting the unnecessary and insignificant. For example, in a typical report

Figure 14.-An example of condensing the prose radiologic report is seen. In (A) the important or essential words are underlined. Other words are unnecessary. In (B) the essential words are soen by themselves. ${ }^{28}$

Excretory Urogram: The renal transplant soft tissue density is present in the left iliac fossa and measures about $16.2 \mathrm{~cm}$. in length. Previous films since the recent transplantation are not available for comparison as to change in renal size. No opaque calculi are demonstrated. Bony structures again show the changes of diffuse generalized loss of bone density and changes of aseptic necrosis involving the femoral head bilaterally. Again previous films are not available.

Following the injection of contrast material, there is slight delay in contrast excretion with subsequent delineation of the collecting system and proximal portion of the ureter by 15 minutes. Collecting system and ureter are slightly full. The distal ureter is not demonstrated. There is extravasation of contrast-laden urine laterally and inferiorly with impingernent of the urine collection on the left lateral superior aspect of the bladder. Also contributing to the imprint is the inferior margin of the transplanted kidney. The bladder is only partially distended but is intrinsically grossly normal.

IMPRESSION: 1. Mild hydronephrosis and hydroureter with leak of urine presumable from the ureter at the site of previous uretero-ureteral anastomoses.

Figure 14a.

Australasian Radiology, Vol. XVI, No. I, March, 1972 


\section{SIGNIFICANT WORDS \\ Renal Transplant \\ 16.2 in length \\ Left Iliac Fossa}

Aseptic Necrosis Femoral Head Bilaterally

Delay in contrast excretion

Collection system and ureter slightly full

Extravasation of contrast-laden urine

Mild hydronephrosis and hydroureter with leak of

urine from ureter at uretero-ureteral anastomosis.

Fioure 148.

of an excretory urogram, two-thirds of the words were found to be irrelevant (Figure 14a). When a computer format is used, the report of the same examination appears in the form of Figure 14b. The adoption of a computer format results in savings in typists' time, but savings in time of the radiologist in his dictation could not yet be shown, at least in the initial period of use by the radiologist.

Another solution to the computer input problem is to present the radiologist with lists or matrices in which types of examinations, anatomic terms, pathological or etiological diagnoses, and modifying words and phrases are offered in turn. The radiologist chooses the appropriate items to fit his interpretation of the examination. The lists or matrices being offered on a video display unit is an additional refinement of this system. $22,24,26,29$

The report can be encoded to simplify and make economical inserting anrd ietreving it from the computer. With encoding one of the developed programmes can place 4,000 pages of reports on one reel of magnetic tape. ${ }^{22}$ Encoding entails the conversion of verbal information to alphanumeric data either by the radiologist or a clerical assistant.23 A special typewriter is available which produces data suitable for computer reception on punched paper tape. ${ }^{12}$, 22 Stored coded material can be translated back into verbal information upon command. ${ }^{23}$ Most of the input techniques simultaneously produce a hard copy of the report as the information is placed in the computer.

At the University of Nebraska, 27 the radiologist dictates onto a magnetic belt. As the typist listens to the belt, she places the report on a CRT display terminal by a keyboard input (Figure 15). The report is then placed in the computer, and a printout made for the patient's record, the copy to the referring physician and one for the film jacket. Standarized reports are designated by the dictating radiologists code number. The computer has stored within it a

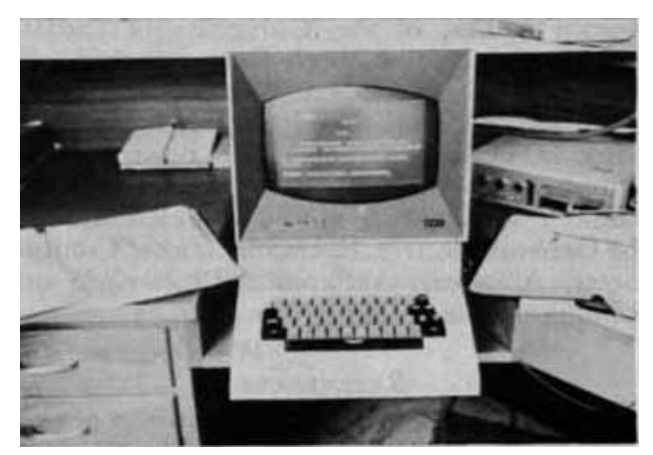

Fioure 15. - The prose radiology report can be placed in the computer at the University of Nebraska with the report appearing on the screen as the typist transcribes it from a dictating machine. Errors can be discovered and corrections made. ${ }^{27}$ (Photo Courtesy of $\mathrm{Wm}$. R. Wilson, M.D.).

report which will print out as prose upon the use of a code number, but the code number itself is stored by the computer for the patient's report, thus saving computer space. Proofreading of the printout is possible with the corrected report being substituted in the computer, and a new printout made. 27 Proofreading of computer reports can be performed also by a display of reports to the radiologist on a computer terminal, correction of reports with a light pen, and placement of the corrected report in the computer. 29 Regardless of the ways, complexities, and difficulties of placing information into the computer, it may be retrieved immediately or at a future time at any location in the hospital or clinic only limited by the number of peripheral units employed. The designing of coded reports for computer use would assist the less experienced radiologist in making a complete report.

\section{SUMmary}

Communication in the diagnostic radiology department in regard to the current work load has been discussed with certain recommendations being made to increase efficiency. The need for improvement in communication equipment and techniques is necessitated by problems facing diagnostic radiology today.

\section{ACKNOWLRDGEMENT}

The author is indebted to Doctor John Thornbury and Doctor Fred Patterson for development of many of the applications of means of communication in radiology as herein described. Very influential also has been Doctor 


\section{HARRY W. Fischer}

Roscoe Miller, of the University of Indiana School of Medicine, both from personal contacts and his published "Radiograph Filing Facilities and Loan Service".14 Doctors E. R. King, H. D. Rosenbaum, E. S. Lodwick, W. R. Wilson, and Mr. L. R. Griewski supplied valuable information as did representatives of the General Electric, Nyematic, Victor Comptometer, American Automatic Typewriter, and Remington Rand Companies.

\section{REFERENCES}

1Puijlacrt, C. B. A. J. (1969): "The expansion of radiodiagnostics." Medicamundi 14, 137-149.

National Advisory Committee on Radiation (NACOR) Report to the Surgeon General, U.S. Public Health Service on Protecting and Improving Health Through the Radiological Science. U.S. Department of Health, Education and Welfare. Public Health Service. April, 1966.

"Dowdy, A. H. (1964) : "Trends in the Academic Teaching of Diagnostic Radiology and Research Possibilities." 7. Med. Educ., 39, 1042-1047.

"Knowles, J. H.: "Radiology-A Case Study in Technology and Manpower." $\mathcal{N}$. Eng. $\mathcal{F}$. Med., 200, 1271-1278, June 5, 1969, and 1323-1329, June 12 1969.

'Report on a Study of Academic Radiology under the auspices of the Division of Medical Sciences, National Research Council. National Academy of Sciences, Washington, D.C., 1969.

Jacobson, H. (1967): "Seduction for a Cause." J. Ass. Canadian Radialogists, 18, 238-239.

${ }^{7}$ Campbell, J. A., Lieberman, M., Miller, R. E., Dreesen, R. G. and Hoover, C. (1969): "Experience with technician performance of gastro-intestinal examinations." Radiol., 92, 65-73.

BAlcorn, F. S., and O'Donnell, E. (1969): "The training of non-physician personnel for use in a mammography program." Cancer, 23, 879-883.

'Rosenbaum, H. D., University of Kentucky, Lexington, Kentucky: "Personal communication."

10Dockray, K. T. (1968): "Timed work steps during diagnostic radiography: operation analysis of $x$-ray examinations for 9200 patients. Radiol., 91, 494-500.

"Barnhard, H. J., and Long, J. M. (1966): "Computer Auto coding, Selecting and correlating of Radiologic Diagnosis Cases. A Preliminary Report. Am. J. Roentgenol, 96, 854-863.

12Barnhard, H. J., and Dockray, K. T. (1970): "Computerized Operation in the Diagnostic Radiology Department." Am. J. Roentgenol, 109, 628-635.
${ }^{13}$ King, E. R., Medical College of Virginia, Richmond, Virginia: "Personal communication."

"Communication, Victor Comptometer Corporation, Chicago, Illinois.

${ }^{15}$ Miller, R. E. (1962): "Radiograph Filing Facilities and Loan Service at the Indiana University Medical Center." Med. Radiography E Photography, 38.

${ }^{16}$ Communication, General Electric Company, Milwaukee, Wisconsin.

${ }^{17 G r i e w s k i, ~ L . ~ R ., ~ U n i v e r s i t y ~ o f ~ M i c h i g a n, ~ A n n ~ A r b o r, ~}$ Michigan: "Personal communication."

${ }^{18}$ Miller, E. R., and McCurry, E. M. (1969): "Immediate Hospital-wide Access to X-ray Film Images." Radiol, 92, 225-230.

19 Communication, Nyematic Company, 30560 Grand River, Farmington, Mich.

${ }^{20}$ Communication, American Automatic Typewriter Company, 2323 N. Pulaski Road, Chicago, Illinois.

"Miller, E. R., McCurry, E. M. and Hruska, B. B. (1969) : "Immediate Remote Access to Radiologist's Reports." Radiol., 92, 13-16.

"Korein, J. Kricheff, I., Chase, N. W., and Randt, C. T. (1965): "Computer Processing of Neuroradiological Reports." Radiol, 84, 197-203.

${ }^{2 x}$ Templeton, A. W., Lodwick, G. S., and Turner, A. H. (1965): "RADIATE: A New Concept for Computer Coding, Transmitting, Storing, and Retrieving Radiological Data." Radiology, 85, 811-817.

${ }^{24}$ Schaefer, P., and Koeppe, P. (1970): "ORVID. A New System for on-line Application of a Computer in the Radiodiagnostic Department." Australian Radiology, 14, 88-91.

${ }^{25}$ Pendergrass, A. P., Greenes, R. A., Barnett, G. O. Poitras, J. A., Pappalardo, A. N., and Marble, C. W. (1969): "An On-line Computer Facility for Systemized Input of Radiology Reports." Radiol., 92, 709-713.

2Uber, G. T., and Baker, H. L. (1968): "System for Recording Neuroradiologic Diagnoses in a Computer." Radiol., 91, 241-247.

${ }^{27}$ Communication, W. R. Wilson, M.D., Department of Radiology, University of Nebraska School of Medicine, Omaha, Nebraska.

28Thornbury, J. R.: The Radiologist as a Reporting Computer Presented at the 17th Annual Meeting of the Association of University Radiologists, San Francisco, California, May 9, 1969.

"Brolin, 1.: "Current Studies in Data Processing of Radiological Reports." SJURA Radiological Croup. Published by Data Saab. 8003E. 